\section{Medical Principles \\ and Practice}

\section{Nasra M. Shah a}

Makhdoom A. Shah ${ }^{\mathrm{b}}$

Zoran Radovanovic ${ }^{\mathrm{a}}$

a Faculty of Medicine,

Kuwait University, and

${ }^{b}$ Faculty of Allied Health Sciences and Nursing, Kuwait University,

Kuwait

\title{
Towards Defining Socioeconomic and Demographic Inequalities That May Affect Health in Kuwait
}

\section{Key Words}

Social class measurement

Socioeconomic status

Social inequalities in health

Socioeconomic score

Socioeconomic status and health

\begin{abstract}
The experience of several developed Western countries shows that mortality and health differences between socioeconomic groups continue to persist, and may even be increasing. However, there is no agreed upon, or 'standard' way of measuring socioeconomic status (SES). In Kuwait questions pertaining to social inequalities in health, and accurate measurement of SES remain to be answered. This paper presents several ideas about the variables that should be examined to define SES. Characteristics of women residing in the most developed and least developed areas are compared to assess the range of inequality in the country. Except for literacy levels, large differences exist for most variables. Previous research and data do not provide a clear idea of any systematic difference in health by social class. This may be partially a result of weaknesses in measurement. The need for reliable data on outcome measures of health as well as indicators of social class is emphasized.
\end{abstract}

\section{Introduction}

As health improves and mortality declines in a country, such changes are often not spread equally throughout the population.

\begin{tabular}{ll}
\hline KARGER & (1 1998 S. Karger AG, Basel \\
Fax +4161306 12 34 & \\
$\begin{array}{l}\text { E-Mail karger@karger.ch } \\
\text { www.karger.com }\end{array}$ & $\begin{array}{l}\text { This article is also accessible online at: } \\
\text { http://BioMedNet.com/karger }\end{array}$
\end{tabular}

The experience of several developed Western countries shows that despite very low levels of mortality, differentials are still present among groups with different socioeconomic statuses (SES) [1-6]. Despite the impressive declines

Dr. Nasra M. Shah

Faculty of Medicine, Kuwait University,

PO Box 24923, Safat 13110 (Kuwait)

Tel. (965) 531 2300, Fax (965) 5338948 ,

E-Mail nasra@hsccmail.kuniv.edu.kw 
in the overall levels of mortality, differences between socioeconomic groups continue to persist, and may even be increasing in some countries [7]. It is generally agreed that in countries with very low levels of mortality, additional declines may depend greatly on reducing social class differences in mortality.

While such differences have been observed, there is no agreed upon, or 'standard' way of measuring SES internationally or even within the same country. Also, the terms social class, and SES, are often used interchangeably. It is being felt widely that more precise definitions of social inequalities are necessary to adequately capture social differentials in health in a society [8-11]. Kuwait is an oil-rich country where the questions pertaining to social inequalities in health as well as the measures that would best define SES remain to be answered fully. The goal of this paper is to present several ideas on the latter question, i.e. on how to define SES in Kuwait, and assist in conceptualizing social class.

The questions pertaining to inequalities have not been explored in a systematic manner. There is no official definition to rank Kuwaitis in the social hierarchy. Indicators such as education, occupation, income, or some combination of these have usually been used to measure socioeconomic differences in health $[12,13]$. There is no consensus on which indicators best capture social class differences or inequalities in the country.

The country is experiencing very rapid development whereby mortality is declining and life expectancy is increasing. The infant mortality rate, for example, declined from about 65 per 1,000 live births in 1965 to only about 12 in 1995 [12, 14]. In terms of SES differences that might exist despite the overall decline, only a few studies exist. Based on 1975 Census data, Kohli and Al-Omaim [15] reported that a consistent inverse association existed between the proportion of dead chil- dren and education level of the mother. Shah and Shah [12] reported on the basis of a national survey conducted in 1984-1985 that the average number of stillbirths was inversely associated with the monthly income of the household. More recent analysis of fetal mortality [16] and child morbidity due to diarrheal disease [Shah et al., unpublished data] have failed to reveal any systematic differences by SES indicators. Furthermore, the published data for 1993-1995 on infant mortality do not provide a systematic picture of mortality differences across the apparently more developed and less developed geographical regions [14].

As the research on assessing socioeconomic differentials in health and mortality moves forward, one of the obvious methodological issues is to address the measurement of SES in the country, especially in view of the fact that Kuwait has an active welfare philosophy aimed at reducing disparities among the nationals. Reliable data on mortality differences according to education, occupation, or residence are lacking, mainly due to the large number of missing data on the notifications of birth and death [17].

The country is fairly homogeneous in terms of its level of urbanization and infrastructure development. About $98 \%$ of the population is living in urban areas with easy access to paved roads, water and electricity supply, sewage facilities, schools, supermarkets, and health facilities [18]. Despite the above types of homogeneity, there seems to be a popular consensus that some areas where Kuwaiti nationals live are more 'backward' than others. There also seems to be a popular consensus that among the five major administrative regions (governorates), Jahra is the least developed while the Capital is the most developed. Published data from the Public Authority for Civil Information (PACI) that has been the main source of population data 
since the 1985 Population Census does not provide enough disaggregation of results to draw a comprehensive comparison of the two areas. Also, the data from the 1995 Population Census are only available in summary form to date [19].

The objective of this paper, therefore, is to present a detailed socioeconomic and demographic comparison of the least developed and most developed areas and describe the extent of differences between them. This is needed in order to arrive at some conclusion about the variables that should be examined before deciding on any meaningful definition of SES in Kuwait. Mapping out such a profile is important to spell out the degree of inequality between various parts of the country, since such inequality may be related to important health indicators pertaining to mortality and morbidity. This paper provides an example of the type of analysis that is necessary to understand socioeconomic differences among various areas of Kuwait. It aims to specify the indicators that must be considered in measuring social class, and suggests one possible way of developing a socioeconomic scale.

\section{Data}

The study is based on interviews conducted during January to March 1994 with all ever-married women residing in the sampled households amounting to 324 households in the Capital and 322 in Jahra. The number of women interviewed was 514 in the Capital and 609 in Jahra. Our sample size was fairly large and for most variables included in the analysis, the margin of error was less than $3 \%$ at the $95 \%$ confidence level. Women in each area were selected through a multistage stratified random sampling procedure. Our survey included only Kuwaiti nationals who in mid 1994 constituted about $38 \%$ of the total inhabitants numbering 1.75 million [20]. Non-Kuwaitis consist mainly of temporary migrant workers, with a large predominance of males in working ages. Questions pertaining to social inequality between the Kuwaitis and non-Kuwaitis (or between various subgroups among non-Kuwaitis), while important, are beyond the scope of the present paper. The following multistage stratified sampling procedure was used. Each of the five major regions (governorates) in Kuwait is composed of subunits known as districts (mantaqas), each of which is further broken down into subdistricts (qitaas). A listing of all mantaqas and qitaas within the two governorates was obtained from the PACI together with the number of households and number of persons in each. Based on the above information, five mantaqas from Jahra and four from the Capital were randomly selected.

From each of the selected mantaqas, one qitaa was randomly selected for inclusion in the study. Thus, nine qitaas were chosen. Within each qitaa we selected every second household using a list obtained from the PACI including the name of the household head, address and telephone number of the households. Within each household, all members who usually live and eat together were listed and information was collected on the socioeconomic characteristics of each person and his/her relationship to the household head. From this listing all those women who were currently married, widowed, or divorced (regardless of age) were included in the study by conducting a face-to-face interview. The percentage of women who refused the interview was $2 \%$ in Jahra and $4 \%$ in the Capital. In case of respondents who were not at home at the first visit by the interviewer, repeat visits were made until the respondent was available. The analysis in this report is based on data collected for each member of the household as well as individual interviews with ever-married women.

\section{Results}

Seven major types of sociodemographic characteristics are examined, as follows: (1) housing and living conditions, and family type; (2) age and sex composition; (3) marital status, consanguinity and polygyny; (4) educational level of men and women; (5) economic activities of men and women; (6) income and salary, and (7) social class distributions.

\section{Housing and Living Conditions}

Kuwaiti nationals reside in two main types of housing, villas they have built or government housing provided to any Kuwaiti who is 
Table 1. Characteristics of households in the Capital and Jahra

\begin{tabular}{|c|c|c|}
\hline Characteristics & $\begin{array}{l}\text { Capital } \\
(\mathrm{n}=324)\end{array}$ & $\begin{array}{l}\text { Jahra } \\
(\mathrm{n}=322)\end{array}$ \\
\hline \multicolumn{3}{|l|}{ Type of housing, \% } \\
\hline Villa/part of villa & 39.3 & 33.0 \\
\hline Government housing & 43.6 & 62.1 \\
\hline Flat & 5.8 & 1.9 \\
\hline Arabic housing/other & 11.3 & 2.5 \\
\hline \multicolumn{3}{|l|}{ Average - Number of } \\
\hline Persons/household & 8.6 & 11.6 \\
\hline Domestic servants/household & 1.8 & 1.1 \\
\hline Persons/household (excluding domestic servants) & 6.8 & 10.5 \\
\hline Ever-married women/household & 1.6 & 1.9 \\
\hline Currently married women/household & 1.4 & 1.8 \\
\hline Currently married women aged 15-49/household & 1.3 & 1.6 \\
\hline Persons/bedroom ${ }^{1}$ & 1.9 & 2.3 \\
\hline Persons/bathroom ${ }^{1}$ & 2.2 & 3.3 \\
\hline Bedrooms/household & 4.6 & 5.2 \\
\hline Bathrooms/household & 3.9 & 3.6 \\
\hline \multicolumn{3}{|l|}{ Family type } \\
\hline Nuclear & 50.0 & 49.8 \\
\hline Extended 1 & 26.8 & 30.7 \\
\hline Extended 2 & 5.8 & 5.0 \\
\hline Extended 3 & 17.2 & 14.2 \\
\hline
\end{tabular}

Type of family has been categorized on the basis of members living in the household as follows: nuclear = head, and/or spouse, with or without unmarried children; extended $1=$ head and/or spouse, with or without unmarried children, and with married children with/without their families; extended 2 = same as extended 1 , but including head's or spouse's parents; extended $3=$ same as extended 2 , but including any other relatives.

1 Excluding domestic servants. eligible and applies for one. Residence in a villa carries a greater amount of social status than residence in a government house. Government housing often consists of row houses with a similar floor plan and is of two types, middle or low income. Middle income housing consists of a larger plot size and usually has central air-conditioning while the low income housing consists of a smaller plot size and does not have central air-conditioning. Assignment of low versus middle income housing is made on the basis of the applicant's income level. In turn for the house given by the government, a small monthly deduction is made from the salary.

Most villas are also usually subsidized by the government through loans but the residents choose the locality, and build the house. An interest-free loan of up to KD 70,000 (US\$ 231,000), payable through small monthly instalments (about US\$ 300), may be obtained for building a villa. A third type of 
housing is the traditional Arabic style homes, most of which were built by the government and distributed to Kuwaitis two or three decades ago. Older localities in the Capital still have some such homes while the housing in newer localities follows relatively modern architectural designs. The data in table 1 indicates that about $40 \%$ of the Capital residents and one third of the Jahra residents lived in a villa.

The number of bedrooms and bathrooms in the two areas were fairly similar. However, the Jahra households were larger in family size. That is, the average number of persons per household (including domestic servants) was 11.6 in Jahra compared with 8.6 in the Capital. Thus, the density per bedroom and bathroom was considerably higher in the former area. For example, one bathroom was shared by 3.3 persons in Jahra compared with 2.2 in the Capital.

The number of servants a household has may be an important indicator of social class in Kuwait. Earlier studies have shown that even though a majority of households have at least one domestic helper, the number of servants increases with the income level of a household [21]. A comparison of the two areas shows that the percentage of households that did not have any servants was $10 \%$ in the Capital and 24\% in Jahra. The average number of servants per household was higher in the Capital (1.8) compared with 1.1 in Jahra.

\section{Type of Family}

Living arrangements represent one dimension of social change in a community. In developing countries, urbanization is often associated with an increase in nucleation of the family. In traditional cultures, there is a larger preponderance of extended family where several generations may live together. Data in table 1 show that the two areas in our study were very similar with about half of all households living in nuclear families. Among those living in extended families, a majority had married children living with them. In a substantial percentage of families in both areas relatives such as parents or brothers and sisters were also living together with the household head and his family including married and unmarried children.

\section{Age and Sex Composition}

The age composition of a population provides an indication of the amount of dependency there is. While both the areas had a triangular-shaped age-sex pyramid that is typical of high fertility societies, the Jahra population had a much larger concentration in the dependent age-group, less than 15 , shown in table 2. A larger percentage of children aged less than 15 years in Jahra is associated with its higher level of fertility, which in turn is often associated with lower levels of development. The crude birth rate in the Capital was 29.8 as compared to 39.2 in Jahra (data not shown). The finding of a higher birth rate in Jahra in our study is consistent with the data published by the Ministry of Health which reported the crude birth rates in 1994 for the Capital and Jahra to be about 35/1,000 and $42 / 1,000$, respectively [14]. The median age of males was 21 years in the Capital compared to 16 years in Jahra. In case of females, the median ages were 25 and 18 years, respectively. The older median age of women is consistent with the higher life expectancy of women than men in the country. The larger number of females in the Capital households is another indicator of the increasing femaleness of the population resulting from the higher life expectancy of females than males [22]. In the Capital there were only 94 males per 100 females compared to 99 males per 100 females in Jahra (table 2). 
Table 2. Age and sex composition in the Capital and Jahra $(\%)^{1}$

\begin{tabular}{|c|c|c|c|c|}
\hline \multirow[t]{2}{*}{ Age } & \multicolumn{2}{|l|}{ Capital } & \multicolumn{2}{|l|}{ Jahra } \\
\hline & $\begin{array}{l}\text { males } \\
(\mathrm{n}=923)\end{array}$ & $\begin{array}{l}\text { females } \\
(\mathrm{n}=991)\end{array}$ & $\begin{array}{l}\text { males } \\
(\mathrm{n}=1,434)\end{array}$ & $\begin{array}{l}\text { females } \\
(\mathrm{n}=1,455)\end{array}$ \\
\hline$<15$ & 38.6 & 35.5 & 45.0 & 41.1 \\
\hline $15-49$ & 48.4 & 48.3 & 45.8 & 51.1 \\
\hline $50+$ & 12.9 & 9.2 & 9.2 & 7.2 \\
\hline Mean age & 24.6 & 26.0 & 19.8 & 20.5 \\
\hline Median age & 21.0 & 25.0 & 16.0 & 18.0 \\
\hline $\begin{array}{l}\text { Sex ratio } \\
\text { (males/100 females) }\end{array}$ & \multicolumn{2}{|c|}{94.0} & \multicolumn{2}{|l|}{99.4} \\
\hline
\end{tabular}

Excluding domestic servants.

\section{Marital Status Composition}

One of the demographic features that usually accompanies socioeconomic development in a country consists of an increasing age at marriage among females. This is also true in Kuwait. However, large differences are present between the less developed and more developed area (data not shown). Among women aged 30-39, for example, about 22\% women in the Capital were still single when compared to only $4 \%$ of such women in Jahra. Also, among those aged 40 or over about $9 \%$ were single in the Capital compared to none of the women in Jahra. There was also a marked difference in the age at marriage of women in the two areas with the singulate mean age at marriage being 26.2 years in the Capital compared to 23.6 years in Jahra.

Marriage of Kuwaitis to a person of their own nationality is preferred socially and encouraged by government policies. We found that $93 \%$ of the couples in the Capital and about $85 \%$ in Jahra were Kuwaiti nationals. The rest had 'mixed' marriages (data not shown). A woman who marries a non-Kuwaiti is at a special disadvantage since her husband does not have a right to nationality or residence in the country [23]. Thus, a larger per- centage of the Jahra couples were in a socially peripheral or marginalized status than the ones in the Capital.

\section{Literacy and Education}

One of the significant and most commonly used indicators of development consists of literacy and educational level of the population. Among all persons aged 10 or more in the two areas, about $91-93 \%$ of the males and $76-80 \%$ of the females were literate, i.e., had received at least 1 year of schooling. The percent literate was higher in the Capital than in Jahra, especially among older persons, and females. For example, among those women aged $40-49,81 \%$ were literate in the Capital when compared to only $27 \%$ in Jahra (table 3). However, the educational level in these two areas has been changing rapidly resulting in an elimination of differences. Among those aged less than 30, almost all the males as well as females in both areas were literate. These findings are supported very closely by data for the whole country for 1994 [20].

While the differences in literacy rates of the two areas have disappeared, we found a fairly large difference in the percentage of males as well as females who have attained an 
Table 3. Percent of literate ${ }^{1}$ persons by age and sex among all members of the household (ages 10 or more) ${ }^{2}$

\begin{tabular}{|c|c|c|c|c|c|c|}
\hline \multirow[t]{2}{*}{ Age } & \multicolumn{3}{|l|}{ Capital } & \multicolumn{3}{|l|}{ Jahra } \\
\hline & $\begin{array}{l}\text { males } \\
(\mathrm{n}=780)\end{array}$ & $\begin{array}{l}\text { females } \\
(\mathrm{n}=826)\end{array}$ & $\mathrm{M} / \mathrm{F}$ ratio & $\begin{array}{l}\text { males } \\
(\mathrm{n}=1,189)\end{array}$ & $\begin{array}{l}\text { females } \\
(\mathrm{n}=1,236)\end{array}$ & $\mathrm{M} / \mathrm{F}$ ratio \\
\hline 10-19 & 99.5 & 100.0 & 1.00 & 99.4 & 99.2 & 1.00 \\
\hline $20-29$ & 99.5 & 100.0 & 1.00 & 100.0 & 95.0 & 1.05 \\
\hline 30-39 & 98.3 & 96.9 & 1.01 & 93.8 & 51.6 & 1.82 \\
\hline 40-49 & 98.2 & 80.7 & 1.22 & 78.5 & 26.7 & 2.94 \\
\hline 50-59 & 82.2 & 34.3 & 2.40 & 47.6 & 8.4 & 5.67 \\
\hline $60+$ & 55.3 & 9.0 & 6.10 & 43.2 & 5.0 & 8.60 \\
\hline All ages & 92.8 & 80.1 & 1.15 & 90.7 & 76.1 & 1.19 \\
\hline
\end{tabular}

Literacy is defined as schooling of at least 1 grade.

2 Excluding domestics.

Table 4. Educational level of all members of the households by $\operatorname{sex}^{1}(\%)$

\begin{tabular}{|c|c|c|c|c|c|c|}
\hline \multirow{2}{*}{$\begin{array}{l}\text { Educational } \\
\text { level }\end{array}$} & \multicolumn{3}{|l|}{ Capital } & \multicolumn{3}{|l|}{ Jahra } \\
\hline & $\begin{array}{l}\text { males } \\
(\mathrm{n}=780)\end{array}$ & $\begin{array}{l}\text { females } \\
(\mathrm{n}=826)\end{array}$ & $\mathrm{M} / \mathrm{F}$ ratio & $\begin{array}{l}\text { males } \\
(\mathrm{n}=1,189)\end{array}$ & $\begin{array}{l}\text { females } \\
(\mathrm{n}=1,236)\end{array}$ & $\mathrm{M} / \mathrm{F}$ ratio \\
\hline Illiterate, read and write & 7.1 & 19.9 & 0.4 & 9.3 & 23.9 & 0.4 \\
\hline Primary & 7.7 & 7.3 & 1.1 & 8.7 & 9.1 & 1.0 \\
\hline Intermediate & 29.3 & 20.6 & 1.4 & 38.6 & 26.9 & 1.4 \\
\hline Secondary & 29.0 & 24.6 & 1.2 & 29.2 & 27.0 & 1.1 \\
\hline Above secondary & 26.9 & 27.7 & 1.0 & 14.3 & 13.1 & 1.1 \\
\hline
\end{tabular}

education beyond the secondary or high school level in the two areas (table 4). Among males, for example, $27 \%$ of the Capital residents had attained an education beyond the secondary level compared to $14 \%$ of the males in Jahra. Within each area, the sex difference among those with an education beyond the secondary level has almost disappeared, or actually reversed in case of the Capital. For the country as a whole, according to data from PACI, the percentage of those with an educa- tion above the secondary level is slightly higher among women than men (13.6 and 13.5, respectively). However, the number of those with postgraduate education was much higher among men than women, the number of such graduates being 2,188 for men and 587 for women in 1994 [20]. Education at the postgraduate level is predominantly attained overseas and the sociocultural values provide lesser support for the education of women than men in countries outside Kuwait. 
Table 5. Labor force participation of ever-married women by age, marital status and education ( $\%$ employed)

\begin{tabular}{lrrrr}
\hline & Capital & $\mathrm{n}$ & Jahra & $\mathrm{n}$ \\
\hline Total & 31.3 & 514 & 10.2 & 609 \\
\hline Age & & & & \\
$<30$ & 52.5 & 118 & 14.9 & 235 \\
$30-39$ & 55.6 & 144 & 15.6 & 122 \\
$40-49$ & 20.0 & 75 & 4.6 & 131 \\
$50+$ & 2.3 & 177 & 1.7 & 121 \\
\hline Marital status & & & & \\
Married & 37.2 & 374 & 10.6 & 517 \\
Divorced & 41.3 & 46 & 16.7 & 24 \\
Widowed & 3.2 & 94 & 4.4 & 68 \\
\hline Education & & & & \\
Illiterate, read and write & 0.6 & 159 & 0.3 & 295 \\
Primary & 2.9 & 34 & 9.8 & 41 \\
Intermediate & 3.0 & 86 & 5.4 & 112 \\
Secondary & 40.6 & 101 & 15.4 & 91 \\
Above secondary & 68.7 & 134 & 52.9 & 70 \\
\hline
\end{tabular}

\section{Economic Activities}

Like education, participation by women in economic activity outside the house is also an important indicator of development. We found that there was a marked difference between the levels of activity in the two areas. About $31 \%$ of the ever-married women were employed in the Capital as compared with only $10 \%$ in Jahra (table 5). In both areas the participation rates were much higher among the women aged less than 40. In the Capital, more than half of all women aged less than 40 were economically active. Higher work force participation of the younger women is a result of the fact that employment opportunities for women have been increasing in recent years. Low participation rates among the relatively older women also result from the fact that Kuwaiti women are allowed to retire with full benefits only after 15-20 years of service.

In both areas, education up to the secondary or higher level has been a big catalyst of the economic activity of women. Among women with a postsecondary education, $69 \%$ of the ones in the Capital and $53 \%$ of those in Jahra were engaged in some occupation outside the house (table 5). An examination of economic activity by the women's marital status at the time of survey indicates that relatively higher percentages of divorced women were economically active in both Jahra and the Capital. Among the widowed women, who are older in any case, the level of economic activity was negligible in both areas.

While the percentage of economically active women was much lower in Jahra in the pattern of occupational distribution was similar in the two areas. Within each area, over $90 \%$ of employed Kuwaiti women were concentrated in just two occupations, working either as professional and technical workers or as clerical and related workers (table 6). About two thirds of the employed Jahra women and $47 \%$ of the Capital women were working in professional or technical occupations, predominantly as schoolteachers. The second major occupation for women in each area consisted of clerical and related work. Women in this category were 
Table 6. Major occupations of employed women and their husbands $(\%)$

\begin{tabular}{lcc}
\hline Major occupation & Capital & Jahra \\
\hline Women & $(\mathrm{n}=161)$ & $(\mathrm{n}=62)$ \\
Professional, technical and related & 47.2 & 64.5 \\
Administrative and managerial & 1.2 & 0.0 \\
Clerical and related & 45.3 & 27.4 \\
Service workers & 4.3 & 8.1 \\
Agricultural and animal husbandry & 0.6 & 0.0 \\
Production and related & 1.2 & 0.0 \\
\hline Husband, \% & & \\
Professional, technical and related & $(\mathrm{n}=514)$ & $(\mathrm{n}=609)$ \\
Administrative and managerial & 17.7 & 8.0 \\
Clerical and related & 10.7 & 3.6 \\
Sales & 32.3 & 23.0 \\
Service workers & 10.9 & 3.0 \\
Agricultural and animal husbandry & 9.7 & 39.4 \\
Production and related & 3.5 & 2.8 \\
Army men & 8.2 & 4.1 \\
Students & 2.7 & 14.3 \\
Handicapped and do not work & 1.6 & 0.7 \\
& 1.6 & 1.1 \\
\hline In case of retired or dead persons, the last occupation before retirement \\
or death was noted.
\end{tabular}

employed largely as secretaries, receptionists and clerks. The above occupations require a certain level of education, which explains the close association between education and occupation as shown in table 5 .

Male occupation has been an especially important indicator of social class in several European countries, particularly the United Kingdom where an occupational-based stratification system is used to classify the population into five different groups [24]. Data on occupations of the husbands of women in our study, as shown in table 6, indicate that the occupational distribution of men was much more varied than in the case of women. The distribution also varied considerably between the two areas. A majority of the men in the Capital were engaged in clerical and related jobs, employed as secretaries, clerks, or clerical supervisors of various categories. The sec- ond major occupation in the Capital consisted of professional and related workers, employed largely as engineers and teachers. In Jahra, on the other hand, almost $40 \%$ of the men were engaged in service work, employed largely as policemen, firemen, and guards. The second most important category of work for the Jahra men was clerical and related work. A much larger percentage of Jahra men were in the army (14\%) when compared to those in the Capital (3\%). Thus, more than half of the men in Jahra were engaged in occupations to provide security to the country when compared to about $13 \%$ of the men in the Capital. It should be noted, however, that less than 10\% of the men in each area were engaged in production or related work, which in other countries represents 'blue collar' occupations. The latter jobs in Kuwait are performed generally by migrant workers. 
Table 7. Total family income, and per capita income and average salary (in KD per month) for households and earning members

\begin{tabular}{lcc}
\hline Total family income, KD & $\begin{array}{c}\text { Capital } \\
(\mathrm{n}=310)\end{array}$ & $\begin{array}{c}\text { Jahra } \\
(\mathrm{n}=318)\end{array}$ \\
\hline Income groups & & \\
$<1,000$ & 25.1 & 28.6 \\
$1,000-1,499$ & 26.8 & 22.6 \\
$1,500-1,999$ & 21.2 & 15.8 \\
2,000 and above & 22.8 & 31.9 \\
Mean & $1,369.5$ & $1,396.8$ \\
Median & $1,200.0$ & $1,025.0$ \\
SE & 50.5 & 66.9 \\
\hline Per capita income & & \\
$<150$ & 29.7 & 68.2 \\
150-199 & 16.1 & 16.4 \\
200-249 & 19.7 & 8.2 \\
250+ & 34.5 & 7.2 \\
Mean & 236.0 & 142.6 \\
Median & 205.0 & 113.3 \\
SE & 8.8 & 6.5 \\
\hline Salary KD/month of & & \\
Currently employed husbands & 242 & 296 \\
$\quad$ Mean & 899.3 & 701.6 \\
$\quad$ Median & 700.0 & 600.0 \\
$\quad$ SE & 55.5 & 30.1 \\
Currently employed women & $160^{\mathrm{a}}$ & 62 \\
$\quad$ Mean & 437.8 & 446.5 \\
$\quad$ Median & 400.0 & 500.0 \\
$\quad$ SE & 12.3 & 17.9 \\
\hline$\quad$ Excluding 1 case & \\
\hline
\end{tabular}

a Excluding 1 case where salary was not known.

\section{Income and Salaries}

The income level of a person (or a household) is an obvious indicator of SES in the sense that the income level of a family affects the quality and quantity of goods and services it can buy. The income level may be measured in several ways, in terms of total household income earned by all economically active members of the family, in terms of the income per member of the household, or in terms of the average monthly salary of employed per- sons. In a society where about half of the households are extended in nature, one needs to examine the total household income as well as per capita income to arrive at some conclusion about the level of inequality between the two areas. Data on various measures of income distribution are shown in table 7. In about half of the households in each area, the total family income was less than KD 1,500 per month. We found that a larger percentage of Jahra households had a monthly income of 2,000 or more $(32 \%)$ when compared to about $23 \%$ of the Capital households. These findings were reversed, however, once the per capita income for the two areas was calculated, since the Jahra households have a larger average number of people residing in them. The higher total family income in Jahra is apparently a result of more than one earner per household in a larger number of households there than in the Capital. In terms of the per capita income, more than two thirds of the Jahra households had a monthly income less than KD 150 when compared to only $30 \%$ of such households in the Capital. On the other hand, $35 \%$ of the Capital households had a per capita income of KD 250 or more compared to only $7 \%$ of the Jahra households. Thus, in relative terms, Jahra households were relatively poorer if judged in terms of income per capita.

Another indicator of income disparity may be provided by the relative salary level of the wage earners in the two areas. The last panel of table 7 shows the average monthly salary of currently employed men and women. Males in the Capital were reported to earn a median monthly salary of KD 700 as compared to KD 600 earned by Jahra residents. These findings confirm the relatively lower income levels of Jahra residents shown in the second panel of table 7 . 


\section{Social Class Composition}

In a situation where large disparities are present between the two areas in case of some variables while such disparities have greatly narrowed in other cases, any single indicator of social class may be misleading. One may be able to measure social class composition more accurately through a composite measure, including several important indicators. This was done for our data by including the following seven variables: type of housing, number of persons per bedroom, husband's occupation, wife's occupation, per capita income, wife's education, and husband's education. Also, we calculated the score for three different groups (all women, those aged 30-49, and less than 30 years) to capture the changes that are occurring in this transitional society. We divided the women into three groups on the basis of the total frequency distribution whereby the lowest $30 \%$ were grouped as low status, the next $39 \%$ as medium status, and the highest $31 \%$ as high status. The results are shown in table 8 . We found a very marked difference between the SES of women in the two areas. Among women of all ages, about $46 \%$ of those in the Capital and only $20 \%$ of those in Jahra belonged to the high SES. However, the socioeconomic characteristics of the populations are changing rapidly and we found an upward shift in the SES level of women in both areas. For example in the Capital, the percentage of those in the high SES increased from $57 \%$ among those aged $30-49$ to $73 \%$ among those aged less than 30 years; the corresponding percentages for Jahra women were 15 and $33 \%$, respectively.

Despite the upward shift in each area, the difference between the SES of residents of the Capital and Jahra has persisted over the last few years as judged from a comparison of younger and older women. A larger percentage of Jahra residents continue to belong to the lower SES level than the Capital residents.
Table 8. SES of women based on a composite score assigned to seven indicators ${ }^{\mathrm{a}}(\%)$

\begin{tabular}{lccc}
\hline & Capital & Jahra & Total \\
\hline All women & $493^{\mathrm{b}}$ & $601^{\mathrm{b}}$ & 1,094 \\
Low & 12.2 & 43.8 & 29.5 \\
Medium & 42.0 & 36.6 & 39.0 \\
High & 45.8 & 19.6 & 31.4 \\
\hline Women aged 30-49 & 207 & 251 & 458 \\
Low & 7.7 & 59.0 & 35.8 \\
Medium & 35.7 & 25.9 & 30.3 \\
High & 56.5 & 15.1 & 33.8 \\
\hline Women aged $<30$ & 117 & 233 & 350 \\
Low & 1.7 & 20.2 & 14.0 \\
Medium & 25.6 & 47.2 & 40.0 \\
High & 72.6 & 32.6 & 46.0 \\
\hline
\end{tabular}

a The seven variables and the scores assigned to each were as follows:

House: government house/flat/others $=1$, villa $=2$.

Persons per bedroom: $>2=1 ; 1.5-1.9=2 ;<1.5=3$.

Husband's occupation: unemployed/handicapped $=$ 0 ; sales/agriculture/production $=1$; clerical $=2$; service and army $=3$; professional/technical/administration $=4$.

Wife's occupation: unemployed $=0$; others (sales, agriculture etc. $)=1$; clerical $=2 ;$ professional $/$ techni$\mathrm{cal} / \mathrm{administration}=3$.

Per capita income $(K D):<150=1 ; 150-199=2$; $200-249=3 ; 250+=4$.

Wife's education: illiterate/read and write $=1$; $1-8=2 ; 9-12=3 ; 12+=4$.

Husband's education: illiterate/read and write $=1$; $1-8=2 ; 9-12=3 ; 12+=4$.

The above coding scheme was used to construct a SES scale for each woman. Those with a score of 5-11 were grouped as low SES, those with $12-15$ as medium SES and those with 16-24 as high SES. The minimum possible score was 5 while the maximum possible was 24.

b Excluding 21 cases from the Capital and 8 cases from Jahra where information was missing on any of the seven variables for the scale. 
In addition to the tabulation shown in table 8, another scale was constructed by including only five variables reflecting the education and occupation (of each spouse), and per capita income. The findings remained essentially similar to the ones shown in table 8 .

\section{Discussion}

The main conclusion from the comparison of the two areas is that there is good reason to consider the Capital and Jahra as regions that represent a fair amount of socioeconomic and demographic disparity. The Capital had more people living in villas. It had fewer persons per bedroom, a larger number of domestic servants, and a higher per capita income. Demographically, there were marked differences. The Capital had an older population, and a substantially lower crude birth rate. The average age at marriage for women was higher in the Capital, as were the percentages of those remaining single. Also, the percentage of women engaged in economic activity outside the house was much higher in the Capital than in Jahra (31 and 10\%, respectively). A composite index based on a score assigned according to seven different indicators also showed that a much larger percentage of the Capital residents belong to the relatively higher socioeconomic class (46\%) than the Jahra residents (20\%). Despite these differences, one aspect on which the disparities have been eliminated consists of literacy, especially among the younger population. Among those aged 6-29 years, almost all the males as well as females in both areas had completed at least 1 year of schooling. A disparity is still present in the level of education attained, with Jahra residents attaining relatively lower levels than the Capital residents. However, within each area, the sex difference in educational attainment has been eliminated, or even reversed in favor of females.
Whether the disparity between the two areas should become reflected in health outcomes is not obvious from the above analysis alone. There are many other factors that may overcome the apparent disparities observed and must be considered in a comprehensive examination of the effects of social class on health [25]. For example, health care facilities are available free of cost for all citizens, and there are no apparent reasons to think that accessibility might be higher in the Capital than Jahra. A national study of child health conducted in 1987 showed, for example, that the percentage of children who had received all the necessary immunizations for DPT, polio, and measles was $96 \%$ in the Capital as compared to $90 \%$ in Jahra [13]. The same survey showed that there was no difference between the two areas in terms of the ownership of certain durable goods such as a car, a refrigerator, or a television since more than 99\% of all households owned each of these goods. Clean, potable drinking water is available to all residents, Kuwaitis as well as non-Kuwaitis. Electricity is also provided to all residents at highly subsidized rates and is available to all households. All Kuwaiti nationals receive an allowance of KD 50 (US\$ 165) per child. Food is provided at subsidized rates at special ration shops for Kuwaiti nationals. Thus, there are many forces that tend to reduce disparity between various sections of the population. It is possible that in terms of the traditional indicators of SES like the ones used in this paper, most of the Kuwaiti population is now above a threshold level below which the disparities may get reflected in indicators of mortality or morbidity. However, differentials may still be present in case of marginalized groups.

Infant mortality is usually regarded as a measure that is sensitive in terms of picking up the effects of socioeconomic disparity in a country. An observation of the differences in 
infant mortality among Kuwaitis during the last 3 years (1993-1995) does not indicate a consistent pattern of difference between the two areas, the Capital and Jahra health regions, as shown in table 9 according to data from the Ministry of Health [14]. It has been noted elsewhere that there are reporting differences between the health regions, and the above differences in infant mortality may simply be an artefact of differential misreporting from year to year [26]. In a small, low mortality population like Kuwait even small errors in reporting can result in relatively marked differences in rates. Also, reliable data by socioeconomic characteristics of the population are not available from the Ministry of Health to analyze this issue in more depth.

In addition to mortality, morbidity of the various segments may also be affected by a person's social class status. In an analysis of morbidity among children based on the same data set as the present study, we found that there were no significant differences in diarrheal morbidity during the 3 months prior to survey although morbidity due to respiratory illness was significantly higher among children in lower social classes [Shah et al., unpublished data].

Thus, we have documented here that according to the traditional indicators of socioeconomic development, marked differences are still present between the two regions that may be regarded as areas representing the relatively highest and lowest levels of development in Kuwait. However, these differences may result in adverse outcomes in case of some illnesses but not in case of certain others. A possible reason for the lack of difference may be that many other counteracting forces might reduce the impact of social class differences. Finally, one may need to focus especially on marginalized groups, such as the one resulting from mixed marriages, to discern differences in health outcomes. Addi-
Table 9. Infant mortality rate [from ref. 14]

\begin{tabular}{lll}
\hline Year & \multicolumn{2}{l}{ Infant mortality rate } \\
\cline { 2 - 3 } & Capital & Jahra \\
\hline 1993 & 13.5 & 14.3 \\
1994 & 14.2 & 13.7 \\
1995 & 11.9 & 15.9 \\
\hline
\end{tabular}

tional analysis focused on both mortality and morbidity outcomes, is necessary to sort out the effects of social class status on health in Kuwait. One of the efforts necessary in this regard pertains to the quality of routinely collected outcome data on mortality and morbidity which must be improved so that the impact of SES can be examined.

Finally, with regard to measurement of SES level of individuals, several conclusions are important. First, a comprehensive analysis of the demographic and SES differences among groups must accompany the efforts to assess the effects of SES on health. Second, any single measure such as education or occupation may not be sufficient to examine the possible effects of SES on various health indicators. Several indicators, as well as combinations of indicators, should be examined to test the reliability of any associations found between such SES indicators and health. Third, the rapid transitions in some indicators (especially education of both sexes, and occupational participation of females) should be considered when dealing with the health of specific subgroups. Fourth, different combinations of indicators and cutoff points should be examined to identify any high-risk groups. Fifth, once the requisite data on socioeconomic variations in health become available, several indicators should be compared to select the ones that most accurately reflect inequalities in the society. Lastly, further re- 
search and debate including additional indicators not considered in this paper should be encouraged in order to arrive at evaluation tools that would most accurately assess the impact, if any, of social inequalities on health.

\section{Acknowledgments}

We are highly appreciative of the able assistance provided by Mrs. Indu Menon. The paper is based on research funded by Kuwait University (MC 034).

\section{References}

1 Vagerö D, Lundberg O: Health inequalities in Britain and Sweden. Lancet 1989;ii:35-36.

2 Lahelma E, Valkonen T: Health and social inequities in Finland and elsewhere. Soc Sci Med 1990;31:257265.

3 Diderichsen F: Health and social inequities in Sweden. Soc Sci Med 1990;31:359-367.

4 Lagasse R, Humblet PC, Lenaerts A, Godin I, Moens GFG: Health and social inequities in Belgium. Soc Sci Med 1990;31:237-248.

5 Siegrist J: Social differentials in chronic disease: What can sociological knowledge offer to explain and possibly reduce them? Soc Sci Med 1995;41:1603-1605.

6 CDC (Center for Disease Control and Prevention): Poverty and Infant Mortality - United States, 1988. Mortal Morbid Rep 1995;44:922926.

7 Pappas G, Queen S, Hadden W, Fisher G: The increasing disparity in mortality between socioeconomic groups in the United States, 1960 and 1986. N Engl J Med 1993;329: 103-109.

8 Liberatos P, Link BG, Kelsey JL: The measurement of social class in epidemiology. Epid Rev 1988;10: 87-121.

9 Navarro V: Race or class versus race and class: Mortality differentials in the United States. Lancet 1990;336 1238-1240.
10 Wagstaff A, Paci P, Doorslaer EV: On the measurement of inequalities in health. Soc Sci Med 1991;33. 545-557.

11 Krieger N, Moss N: Accounting for the public's health: An introduction to the selected papers from a U.S Conference on Measuring Social Inequalities in Health. Int J Health Serv 1996;26:383-390.

12 Shah NM, Shah MA: Socioeconomic and health care determinants of child survival in Kuwait. $\mathrm{J}$ Biosoc Sci 1990;22:239-253.

13 Al-Rashoud R, Farid S (eds): Kuwait Child Health Survey. Kuwait, Ministry of Health, 1991.

14 DV \& HS (Division of Vital and Health Statistics): Vital Health and Statistics Abstract. Department of Medical Records and Statistics. Kuwait, Ministry of Health, 1993, 1994, 1995.

15 Kohli KL, Al-Omaim MA: Infant and child mortality in Kuwait. J Biosoc Sci 1983;15:339-348.

16 Shah NM, Radovanovic Z, Shah MA: Demographic and socioeconomic factors in early fetal mortality in Kuwait. Paper presented at Middle East Studies Association of North America, Phoenix, Nov, 1994.

17 Shah NM, Shah MA, Al-Sayed A: Quality of birth and death notifications in Kuwait. Med Principles Pract 1992;3:102-114.
18 CSO (Central Statistical Office): Annual Statistical Abstract 1995. State of Kuwait, Ministry of Planning, 1995.

19 CSO (Central Statistical Office): Population Census 1995, April 1123: Preliminary Results. State of Kuwait, Ministry of Planning, 1995.

20 PACI (Public Authority for Civil Information): Directory of Civil Information: Population and Labor Force. Kuwait Government, 1994.

21 Shah NM, Al-Qudsi S, Shah MA Asian women workers in Kuwait. Int Migration Rev 1991;25:464486.

22 PRB (Population Reference Bureau): Population Data Sheet. Washington, 1995.

23 al-Mughni H: Women in Kuwait: The Politics of Gender. Saqi Books. Westbourne Grove, London, 1993 , vol 26.

24 Blane D: Inequality and social class in sociology as applied to social class; in Scambler G (ed): Sociology as Applied to Medicine. London, Baillière Tindall, 1991.

25 Shah NM, Shah MA: Mortality and morbidity transition in Kuwait: The role of health and development policies. Int J Health Planning Manage 1987;2:183-200.

26 Shah NM, Khalaf AA: Do birth and death notifications cover all events that occur in Kuwait hospitals? J Kuwait Med Assoc 1996;28:472475 . 